\title{
Caracterização de feições do embasamento na parte central da Bacia dos Parecis
}

Santos, I.N., La Terra, E.F, Fontes, S.L.

Observatório Nacional, Rio de Janeiro, RJ, Brasil.

Copyright 2014, SBGf - Sociedade Brasileira de Geofísica

Este texto foi preparado para a apresentação no VI Simpósio Brasileiro de Geofísica, Porto Alegre, 14 a 16 de outubro de 2014. Seu conteúdo foi revisado pelo Comitê Técnico do VI SimBGf, mas não necessariamente representa a opinião da SBGf ou de seus associados. E proibida a reprodução total ou parcial deste material para propósitos comerciais sem prévia autorização da SBGf.

\section{Resumo}

A Bacia dos Parecis é uma das maiores bacias intracratônicas em território brasileiro e possui uma área de aproximadamente $500.000 \mathrm{Km}^{2}$. Está localizada na região Centro-Oeste do Brasil onde ocupa parte dos estados de Mato Grosso e Rondônia. Esta bacia é segmentada tectonicamente em três domínios: Fossa tectônica de Rondônia à oeste, Baixo Gravimétrico na região central e uma sub-bacia do tipo sag na porção leste (Siqueira, 1989 e Pedreira et al, 2003), (Fig.1).

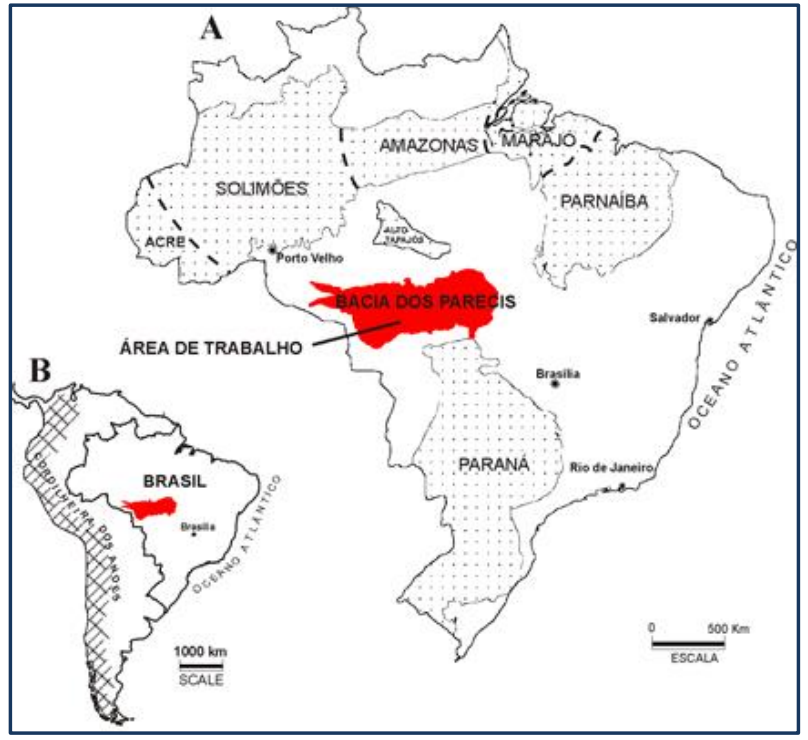

Figura1: Mapa de localização da Bacia dos Parecis (Bahia, 2007).

Este trabalho consiste na avaliação, processamento e interpretação de dados aeromagnéticos de parte da Bacia dos Parecis. Para isto foram gerados e observados mapas de Campo Magnético Residual, Sinal Analítico, derivadas de primeira ordem, direção preferencial de lineamentos estruturais e ainda Deconvolução de Euler.
Esses dados serão usados futuramente na integração com dados gravimétricos e de levantamentos magnetotelúricos e são de grande importância para o entendimento da história evolutiva da Bacia.

\section{Introdução}

Existe um grande interesse no estudo e entendimento das bacias sedimentares brasileiras, sobretudo das bacias intracratônicas que podem alcançar grandes profundidades de sedimentação e quase sempre derrames magmáticos, contribuindo assim para o aumento do potencial petrolífero dessas bacias. Dentre elas a Bacia dos Parecis é a que mais carece de estudos para um melhor entendimento de sua geologia.

Estima-se que a Bacia dos Parecis, que está localizada na região do centro-oeste brasileira e possui extensão de área de aproximadamente $500.000 \mathrm{Km}^{2}$, tenha acumulado sedimentos a profundidades de aproximadamente $6.000 \mathrm{~m}$. Esta bacia está localizada na região sudoeste do Cráton Amazônico entre as Bacias do Paraná e dos Solimões e tem como limite a sul e a sudoeste os Arcos do Alto Xingu e do Rio Guaporé respectivamente, sendo seus limites nas demais direções as rochas do próprio embasamento Neoproterozóico.

A Bacia dos Parecis se divide em três domínios tectônico-sedimentares que separa a bacia em três subbacias. O limite entre essas sub-bacias se dá de leste para oeste pelo Arco de Vilhena e Arco de Serra Formosa (Siqueira e Teixeira, 1993). A sub-bacia a oeste é formada por uma depressão tectônica (sub-bacia de Rondônia), a região central é identificada como um baixo gravimétrico da ordem de $-40 \mathrm{mGal}$ (sub-bacia do Juruena) e a região leste é interior tipo sinéclise (subbacia do Alto Xingu) (Siqueira, 1989 e Pedreira et al, 2003). Os sedimentos que preenchem a bacia são sedimentos, predominantemente siliciclásticos, que 
datam do paleozóico, mesozóico e cenozóico. As rochas sedimentares que compõem a bacia possuem níveis ricos em matéria orgânica com potencial para geração de hidrocarbonetos. No inicio do Paleozóico a região da Bacia dos Parecis foi afetada por um evento tectônico extensional que afetou parte do Cráton Amazônico. Acredita-se que a Bacia dos Parecis tenha evoluído a partir de um riftes percussores intracontinentais de direção W-E que seria responsável pela implantação dos Grábens do Colorado e de Pimenta Bueno e também pela compartimentação tectônica de grande parte da bacia. Estruturalmente a bacia apresenta altos e baixos estruturais ao longo de toda a sua extensão. Ocorrem ainda na bacia lineamentos estruturais de direção preferencial NW-SE, comum às demais bacias oriundas do Cráton Amazônico tais como Bacia do Amazonas e dos Solimões. Apesar de já conhecida a ocorrência de algumas exsudações de gás, o sistema petrolífero dessa bacia é ainda desconhecido e necessita de trabalhos geológicos e geofísicos que possam colaborar para um melhor entendimento da bacia. Nesse trabalho foram utilizados dados aeromagnéticos (Fig. 2), tendo como objetivo o processamento e a interpretação dos mesmos a fim da caracterização de estruturas e profundidades do embasamento. Futuramente esses dados serão utilizados na integração e interpretação conjunta junto a dados de levantamentos magnetotelúricos.

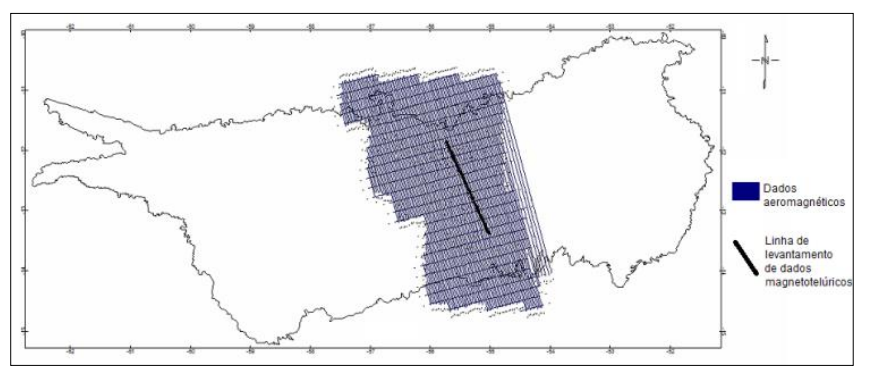

Figura 2: Mapa de indicando área do levantamento aeromagnético junto com dado MT que será integrado aos resultados futuramente

\section{Metodologia}

As etapas de processamento e interpretação de dados foram feitas baseadas em dados aeromagnéticos cedidos pela ANP através de programa de cooperação técnica ente o Observatório Nacional e a ANP.

As linhas de voo utilizaram a direção N15W e estão espaçadas a cada $3000 \mathrm{~m}$. Os dados foram medidos a uma elevação de $1000 \mathrm{~m}$. O mapa das anomalias de campo total foram gerados pelo método de gridagem bidirecional onde foi usada células de $750 \mathrm{~m}$. Após essa etapa o dado foi micronivelado para remover diferenças na altitude de vôo. Nessa etapa de micronivelamento foi utilizado o método de decorrugação com aplicação dos filtros: Butterworth e Coseno Direcional.

Depois desta etapa foi aplicado o filtro de Continuação para cima que elevou os dados para uma altitude de $2000 \mathrm{~m}$ a fim de que fossem removidos os ruídos presentes no dado e/ou anomalias de curto comprimento de ondas superficiais sem que houvesse distorção das informações adquiridas.

Após aplicação dos devidos filtros e da remoção de trend foram gerados mapas do Campo Magnético Residual, Amplitude do Sinal Analítico (ASA), Derivadas direcionais de $1^{\text {a }}$ ordem (Dx, Dy e Dz), tendência de lineamentos magnéticos e Deconvolução de Euler.

Os mapas de lineamentos magnéticos visam a observação de tendências preferenciais de estruturas de lineamento que ocorrem na região enquanto que o Deconvolução de Euler implica na obtenção da estimativa da profundidade das fontes das anomalias magnéticas.

\section{Resultados}

O mapa do campo magnético residual (Fig. 3) foi obtido após os processos de micronivelamento e de continuação para cima. A interpretação desse mapa requer certo cuidado ao ser interpretado devido à presença de dipolos magnéticos que mudam de comportamento de acordo com a anomalia magnética e a latitude de observação. No mapa de campo magnético residual podemos observar anomalias da ordem de até 206 nT. 


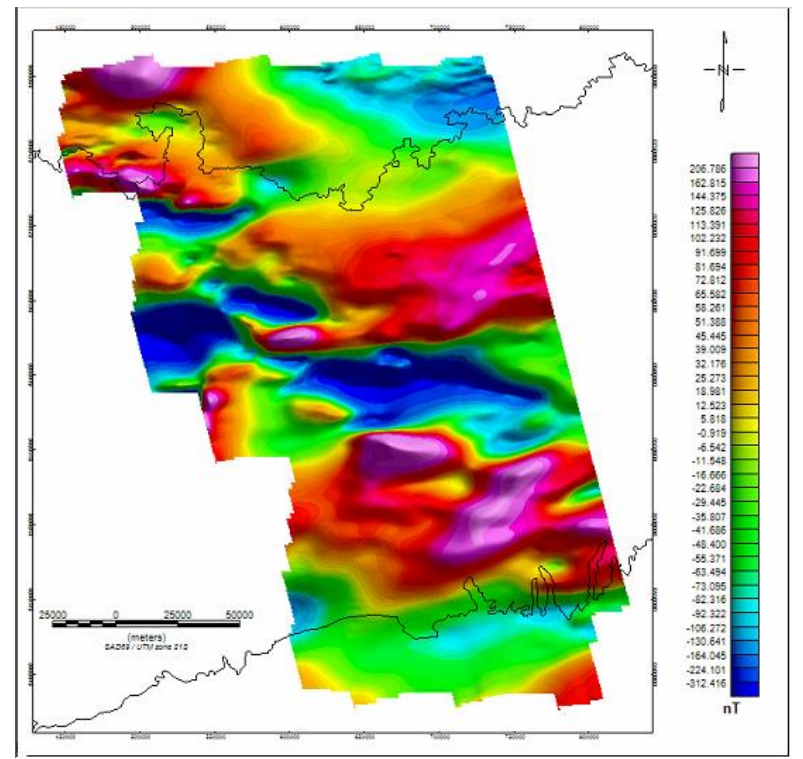

Figura 3: Mapa do Campo Magnético Residual

O calculo das derivadas direcionais permitem analises da geometria e indica variações nos dados baseadas no calculo do gradiente. Foram calculadas derivadas de $1^{\underline{a}}$ ordem para as direções $\mathrm{X}, \mathrm{Y}$ e $\mathrm{Z}$. As derivadas horizontais (Dx e Dy) analisam o gradiente horizontal do campo magnético residual e indica mudanças laterais das propriedades físicas. Esse tipo de derivada tende a evidenciar picos localizados acima de suas fontes geradoras (Blum, 1999).

A derivada vertical $(\mathrm{Dz})$ analisa o gradiente vertical do campo magnético residual (Fig. 4) e tende a evidenciar nas fontes causadoras de anomalias magnéticas com altos contrastes da propriedade magnética, podendo identificar estruturas lineares correspondentes as estruturas geológicas que podem estar ligado ao embasamento.

O mapa de Amplitude do sinal analítico (ASA) é feito a partir do módulo da primeira derivada total, ou seja, é baseado no uso de gradientes horizontais e verticais de anomalias de campos potenciais. É aplicado de acordo com a seguinte expressão:

$$
|A(x, y)|=\left[\left(\frac{\partial M}{\partial x}\right)^{2}\right]+\left[\left(\frac{\partial M}{\partial Y}\right)^{2}\right]+\left[\left(\frac{\partial M}{\partial Z}\right)^{2}\right]
$$

Onde, A corresponde a amplitude do sinal analítico.

Este método torna as anomalias monopolares. (Roest et al, 1992) e não requer um conhecimento prévio da direção de magnetização. Assim sendo não é necessário o processamento de redução ao polo. (Hsu et al., 1998).

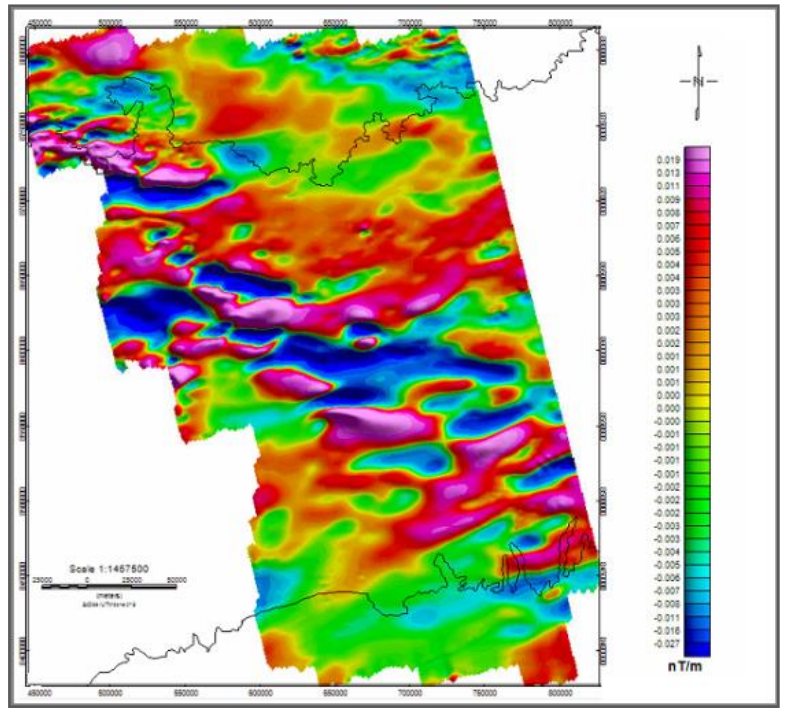

Figura 4: Mapa da derivada vertical de primeira ordem $(D z)$

A amplitude do sinal analítico é uma função simétrica em formato de sino (bell shaped), tendo seu máximo sobre o topo dos contatos e sua largura relacionada com a profundidade do corpo (Nabighian, 1974). Foi gerado mapa ASA, (Fig. 5) a fim da observação dos contatos magnéticos e na utilização para observação de suas profundidades.

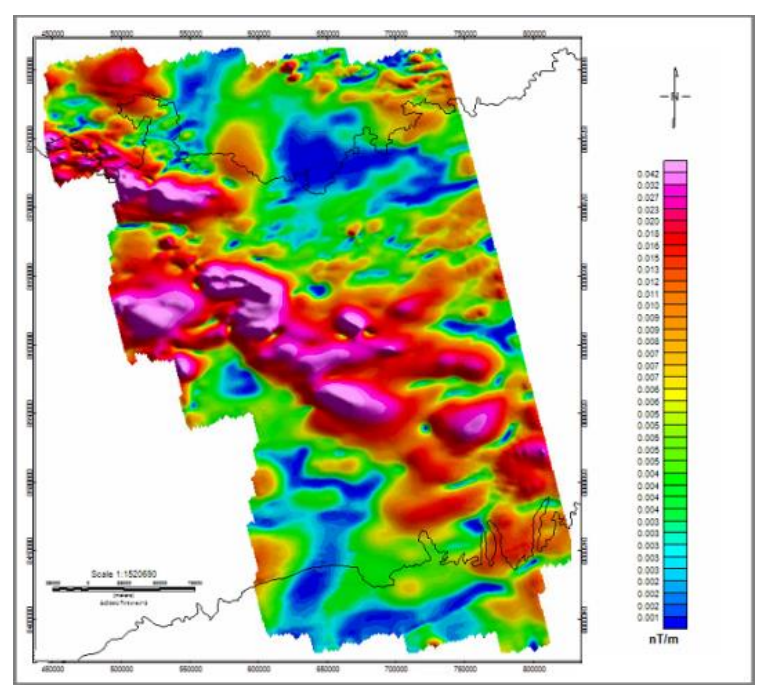

Figura 5: Mapa de Amplitude do Sinal Analítico (ASA) 
Foram feitos também mapas de aplicação de tendências

(Fig.6) lineares magnéticas onde foram traçadas estruturas sobre os picos de máximas amplitudes com o intuito de localizar a direção preferencial de lineamentos magnéticos provenientes da fonte causadora.

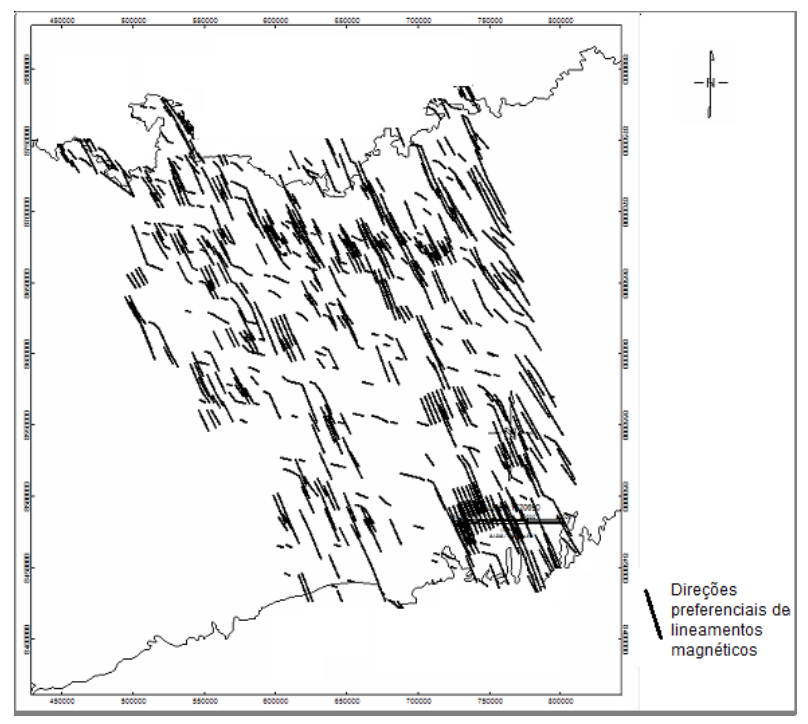

Figura 6: Mapa de tendências magnéticas lineares.

O método da deconvolução de Euler (Thompson, 1982; Reid et al, 1990) é baseado na aplicação da equação homogênea de Euler, a qual relaciona o campo potencial e seus gradientes para localizar a fonte causativa, baseado no grau de homogeneidade que é interpretado como um índice estrutural, relacionado a natureza da fonte, derivando-se, a partir de uma janela móvel fixa, o posicionamento e a profundidade dos corpos.

Para aplicação desse método foi utilizado índice estrutural 1. Esse valor foi usado para proporcionar melhor visualização de fontes magnéticas com feições lineares. Um mapa com valores de profundidades das fontes, evidenciando possíveis profundidades para o topo do embasamento (Fig.7).

\section{Discussão e Conclusões}

Foi observado no mapa magnético residual anomalias com intensidade que variam entre -312 e 206 nT e dispostas de forma a indicar uma tendência de orientação na direção NW-SE. É provável que essa direção preferencial corresponda a estruturas do embasamento e esteja relacionado a um evento de compressão responsável pelo desenvolvimento de um cinturão com estruturas com vergência para NW que é tido como resultado da Orogênese Transamazônica, responsável pela colagem continental.

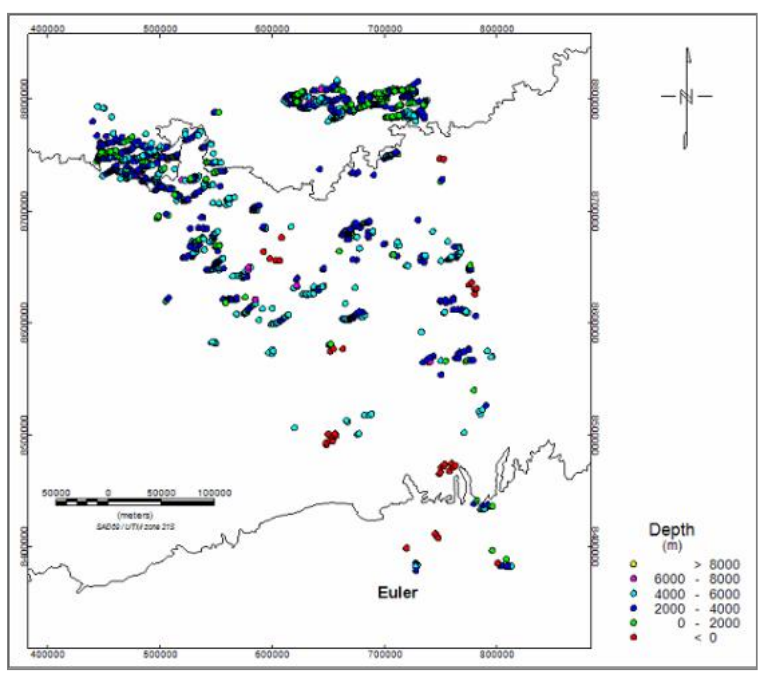

Figura 7: Mapa de Deconvolução de Euler

Essa direção e geometria da fonte causadora foi confirmado com o mapa de ASA para esta região da bacia.

Através do mapa de tendência linear magnética é possível identificar duas tendências preferenciais de lineamentos magnéticos, uma na direção N55W e outra, mais pronunciada, na direção N25W. Essas direções condizem com as direções observadas no mapa de Campo Magnético residual e também no mapa de derivada vertical sugerindo assim que esses lineamentos magnéticos estão presentes nas maiores profundidades da bacia.

A avaliação qualitativa foi feita através do mapa de profundidades gerado gerado por Deconvolução de Euler. Pode-se observar do mapa (Fig. 7) que na região central da área estudada a maior parte das fontes magnéticas está localizada a profundidades que variam entre $4000 \mathrm{~m}$ e $6000 \mathrm{~m}$ podendo chegar, em alguns pontos, a profundidades de até $8000 \mathrm{~m}$. O mapa de 
deconvolução de Euler foi também analisado juntamente com o mapa ASA e pode se observar a ausência de fontes profundas nas regiões de maior intensidade anomalia do ASA indicando assim caracterização de um alto estrutural.

Futuramente serão processados dados aeromagnéticos e gravimétricos para toda a bacia a fim da integração e interpretação conjunta dos dados potenciais com os dados obtidos na linha de levantamento magnetotelúrico. Os resultados irão também contribuir para orientar a direção de rotação dos tensores de impedância do método magnetotelúrico (MT).

\section{Agradecimentos}

Ao Banco de Dados de Exploração e Produção da Agencia Nacional do Petróleo. Gás Natural e Biocombustíveis (BDEP/ANP) pelos dos dados geofísicos utilizados nesse trabalho. Este projeto é financiado pelo termo de Cooperação Técnica entre a ANP e ON, no 001/2013-ANP.

\section{Referências Bibliográficas}

BAHIA, R. B. (2007). Evolução tectônossedimentar da Bacia do Parecis - Amazônia. Ouro Preto: UFOP.

BAHIA R.B.C., MARTINS-NETO M.A., BARBOSA M.S.C. \& PEDREIRA A.J. 2007. Análise e evolução tectonosedimentar da bacia dos Parecis através de métodos potenciais. Rev. Bras. de Geociências, 37(4): 639-649.

BLUM, MLB. 1999. Processamento e Interpretação de Dados de Geofísica no Brasil Central e Sua Aplicação à Geologia Regional e à Prospecção Mineral. In: Técnicas de Tratamento de Dados Geofísicos. Brasília, p 30-33.

HSU, S.K., DOROTHÉE, C., SHYU, C.T., 1998, Depth to magnetic source using the generalized analytic signal: Geophysics, 63:1947-1957.

NABIGHIAN MN. 1974. Additional comments on the analytic signal of two-dimensional magnetic bodies with polygonal cross-section. Geophysics, 39(1): 85-92.
PEDREIRA A. J., LOPES R. C., VASCONCELOS A. M. \& BAHIA R. B.C. 2003. Bacias Sedimentares Paleozóicas e Meso-Cenozóicas. In: Bizzi, L. A.; Schobbenhaus, C.; VIDOTTI, R. M.; GONÇALVES, J. H., 2003, (Orgs). Geologia, Tectônica e Recursos Minerais do Brasil Texto, Mapas e SIG. Brasília, CPRM. p 55-85.

REID, A.B., ALLSOP, J.M., GRANSER, H., MILLET, A.J. E SOMERTON, I.W., 1990, Magnetic interpretations in three dimensions using Euler deconvolution: Geophysics, 55: 80-91.

ROEST , W. R., VERHOEF J. \& PINLKINGTON M., 1992, Magnetic interpretation using the $3 \mathrm{D}$ analytic signal: Geophysics, 57: 116-125

SIQUEIRA L.P. 1989. Bacia dos Parecis. Boletim de Geociências da Petrobrás, 3:3-16

SIQUEIRA L.P. \& TEIXEIRA L.B. 1993. Bacia dos Parecis: nova fronteira exploratória da Petrobrás. SBGf., $3^{\circ}$.Congr. Intern. Soc. Bras. Geof. Anais..

THOMPSON, D. 1982. EULDPH: A new technique for making computer-assisted depth estimates from magnetic data. Geophysics, 47(1), 31-37. 